\title{
The effect of ispaghula (Fybogel and Metamucil) and guar gum on glucose tolerance in man
}

\author{
BY H. A. JARJIS, N. A. BLACKBURN, J. S. REDFERN AND N. W. READ \\ Clinical Research Unit, H Floor, Royal Hallamshire Hospital, Sheffield S10 2JG
}

(Received 19 May 1983 - Accepted 21 November 1983)

1. The effects of incorporating Fybogel ( 3.5 and $7 \mathrm{~g}$ doses), Metamucil ( $7 \mathrm{~g}$ ) or guar gum ( 2.5 and $14.5 \mathrm{~g}$ doses) in a drink containing $50 \mathrm{~g}$ glucose on plasma glucose, plasma insulin and gastric emptying were studied in thirty-eight normal volunteers. In addition, the effects of Fybogel $(7 \mathrm{~g})$ on glucose tolerance, plasma insulin and gastric emptying were measured in fourteen non-insulin-dependent diabetics.

2. Both doses of guar gum significantly lowered plasma glucose and plasma insulin responses to the oral glucose load in normal subjects, although $14.5 \mathrm{~g}$ guar gum did not delay the half-time for gastric emptying.

3. Neither Fybogel nor Metamucil had significant effects on plasma glucose responses in normal subjects. In addition, Fybogel (at either dose) had no significant effects on plasma insulin levels, or on gastric emptying in normal subjects or on plasma glucose and insulin responses in diabetic patients.

4. The viscosity of ispaghula solutions (Fybogel) was lower than that of guar gum solutions.

The addition of viscous polysaccharides such as pectin or guar gum to meals or glucose solutions lowers postprandial plasma glucose and insulin concentrations in normal volunteers (Gassull et al. 1976; Jenkins et al. 1977, 1978; Morgan et al. 1979; Wahlqvist et al. 1979) and diabetic patients (Gassull et al. 1976; Jenkins et al. 1976; Morgan et al. 1979). The effect of these agents appears to be related to their viscosities (Jenkins et al. 1978) and they may inhibit glucose absorption by reducing the convective effect of intestinal motor activity (Blackburn et al. 1984). However, many subjects find that guar gum and pectin are unpalatable taken in the doses that have been shown previously to influence glucose tolerance. This has led to a search for alternative forms of dietary fibre which are more palatable and have a beneficial action on glucose tolerance. Several recent studies (Sartor et al. 1981; Florholmen et al. 1982) have reported that ispaghula husk, a component of several bulk laxatives, may reduce postprandial glucose levels in diabetic patients and may provide an acceptable and palatable form of fibre.

The present study investigated the effect of Fybogel (Reckitt and Colman Ltd, Kingston upon Hull) (given in two doses) and Metamucil (G. D. Searle and Co. Ltd, High Wycombe, Bucks) on plasma glucose and plasma insulin levels following an oral glucose load in normal subjects and in patients with non-insulin-dependent diabetes mellitus. The results were compared with those for guar gum administered in the same manner.

\section{MATERIAL AND METHODS}

\section{Chemicals}

Fybogel was obtained in sachets containing $3.5 \mathrm{~g}$ ispaghula husk from the seeds of Plantago ovata, $0.5 \mathrm{~g}$ sodium bicarbonate, $0.44 \mathrm{~g}$ citric acid and sodium saccharin flavouring. Metamucil was obtained in sachets, each containing approximately $3.5 \mathrm{~g}$ ispaghula husk and an equal amount of anhydrous glucose, $0.9 \mathrm{~g} \mathrm{NaHCO}_{3}, 1.03 \mathrm{~g}$ citric acid and $0.83 \mathrm{~g}$ saccharose. Guar gum, a storage polysaccharide from the cluster bean (Cyamopsis tetragonoloba), was obtained from the Hercules Powder Company, Erith, Kent. 


\section{Subjects}

Studies were carried out on a total of thirty-eight normal healthy subjects (twenty-seven male, eleven female, age range 20-30 years) and on fourteen patients with non-insulindependent diabetes mellitus (twelve male, two female, age range 45-65 years).

\section{Experiments using Fybogel}

\section{Glucose load studies}

Normal subjects. Paired studies were carried out on a total of twenty-two normal healthy subjects (sixteen male, six female). On one occasion, the subjects drank $250 \mathrm{ml}$ of a solution containing $50 \mathrm{~g}$ glucose, $200 \mathrm{ml}$ water, $50 \mathrm{ml}$ diabetic orange squash and $50 \mu \mathrm{Ci}$ ${ }^{98 \mathrm{~m}}$ Technecium ( $\left.{ }^{89 \mathrm{~m}} \mathrm{Tc}\right)$-sulphur colloid. On a second occasion, they drank a similar solution containing either $3.5 \mathrm{~g}$ (nine subjects) or $7 \mathrm{~g}$ (thirteen subjects) Fybogel (14 or $28 \mathrm{~g} / 1$ respectively). This was prepared by stirring the Fybogel into the solution and then allowing the mixture to stand at room temperature overnight to become fully hydrated. The order of the two studies was randomized. The whole-body radiation dose from $50 \mu \mathrm{Ci}{ }^{90 \mathrm{~m}} \mathrm{Tc}-\mathrm{S}$ colloid was less than $1 \mathrm{mrad}$, and total dose to the gonads was less than 5 mrad.

After an overnight fast, the subject drank the glucose solution and then lay supine on a couch. The rate of gastric emptying was determined in fifteen subjects (nine subjects taking $3.5 \mathrm{~g}$ Fybogel and six subjects taking $7 \mathrm{~g}$ Fybogel) by monitoring the decline in radioactivity over the fundus of the stomach using a $\gamma$-camera (Jones et al. 1970).

Venous blood samples were taken from the forearm through an indwelling butterfly needle on two occasions before the drink was ingested and at $30 \mathrm{~min}$ intervals thereafter for a total of $2 \mathrm{~h}$. These blood samples were analysed for glucose (glucose oxidase (EC 1.1.3.4) method) and total insulin levels (radioimmunoassay).

Diabetic patients. The effects of $7 \mathrm{~g}$ Fybogel on plasma glucose and insulin levels and on the rate of gastric emptying following an oral glucose load were studied in twelve male and two female patients with non-insulin-dependent diabetes mellitus.

\section{Experiment using Metamucil}

The effect of $7 \mathrm{~g}$ Metamucil on plasma glucose and plasma insulin responses to an oral glucose load was investigated in eight normal volunteers (six male, two female, age range 20-30 years) using a similar experimental design as that used for the Fybogel studies, but omitting measurements of gastric emptying and plasma insulin. The order of studies was randomized.

\section{Experiments using guar gum}

These were carried out on a total of sixteen healthy normal subjects (eleven male, five female) who drank the glucose solution as described previously with or without $2.5 \mathrm{~g}$ (eight subjects) or $14.5 \mathrm{~g}$ guar gum (eight subjects) (10 or $58 \mathrm{~g} / 1$ ). Measurements of plasma glucose and plasma insulin were carried out as described for experiments using Fybogel and gastric emptying was measured after ingestion of $58 \mathrm{~g}$ guar gum/l using a single-crystal scintillation detector. This method has been found to yield results for gastric emptying which are reproducible and correlate well with measurements obtained with the $\gamma$-camera (Ostick et al. 1976). The order of the experiments was randomized.

\section{Viscosity measurements}

The viscosity of solutions of guar gum and Fybogel at various concentrations ranging from 1 to $20 \mathrm{~g} / 1$ were determined immediately after dispersion at $37^{\circ}$, at $\mathrm{pH} 7.4$ and at a constant shear rate of $50 / \mathrm{s}$ using a Contraves rheomat 15 with the cone-and-plate measuring system 

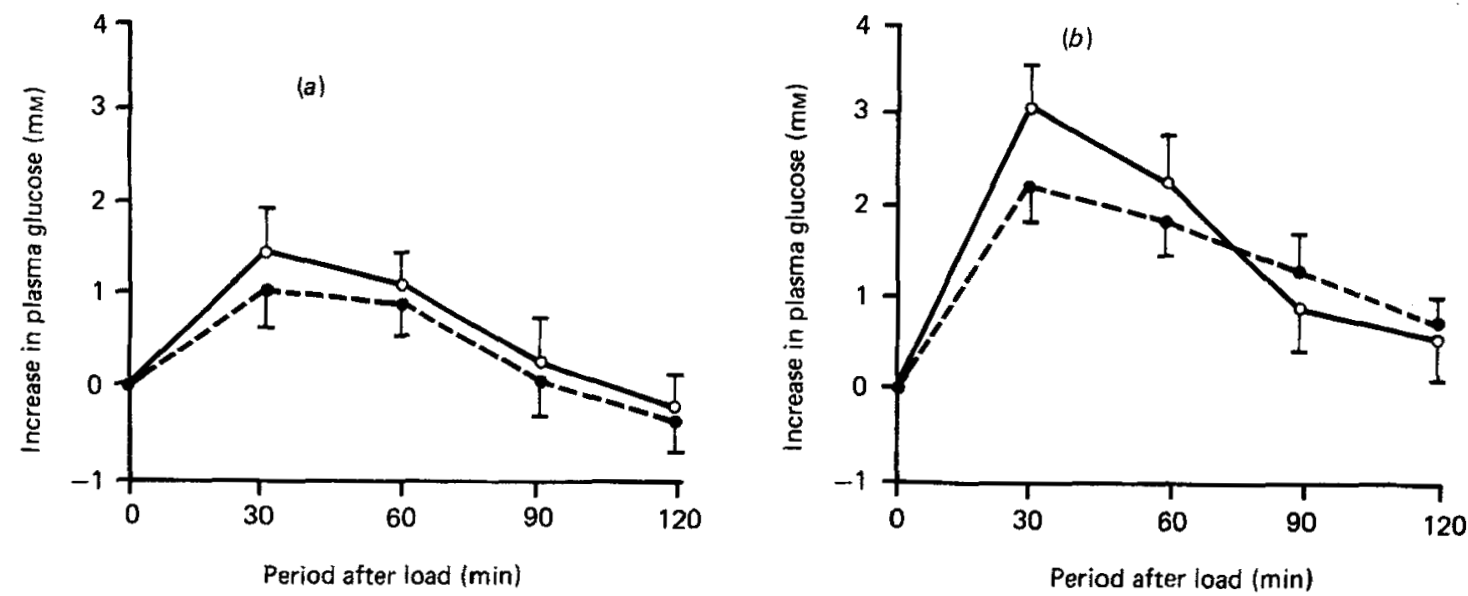

Fig. 1. Increase in plasma glucose leveis (mM) over basal values following ingestion of $50 \mathrm{~g}$ glucose in a $250 \mathrm{ml}$ drink $(O)$ with or $(O)$ without $(a) 3.5 \mathrm{~g}$ or $(b) 7 \mathrm{~g}$ Fybogel in normal subjects. Points are mean values with their standard errors of the mean represented by vertical bars for eight $(a)$ and thirteen $(b)$ observations.

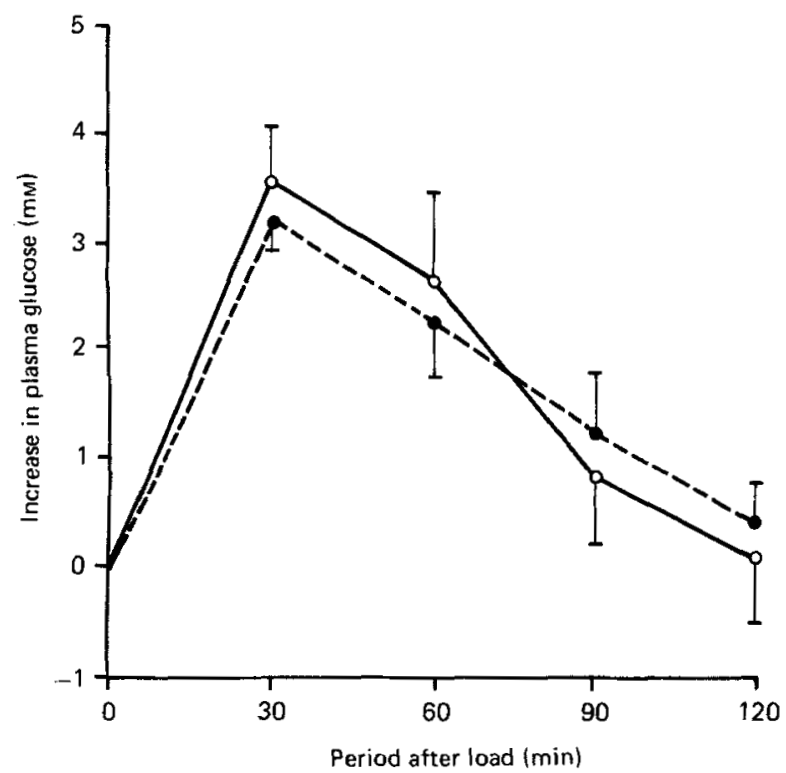

Fig. 2. Increase in plasma glucose levels (mM) over basal values following ingestion of $50 \mathrm{~g}$ glucose in a $250 \mathrm{ml}$ drink (O) with or $(\mathrm{O})$ without $7 \mathrm{~g}$ Metamucil in normal subjects. Points are mean values with their standard errors of the mean represented by vertical bars for eight observations.

(type KPI). All viscosities are presented in units of millipascal seconds $(1 \mathrm{mPa} . \mathrm{s}=1$ centipoise).

\section{Ethical considerations}

All subjects were fully informed concerning the nature of the study and had given their written consent to the proceedings. The protocol was approved by the Ethical Sub-Committee of the Sheffield Health Authority (southern district). Studies on female subjects were carried 

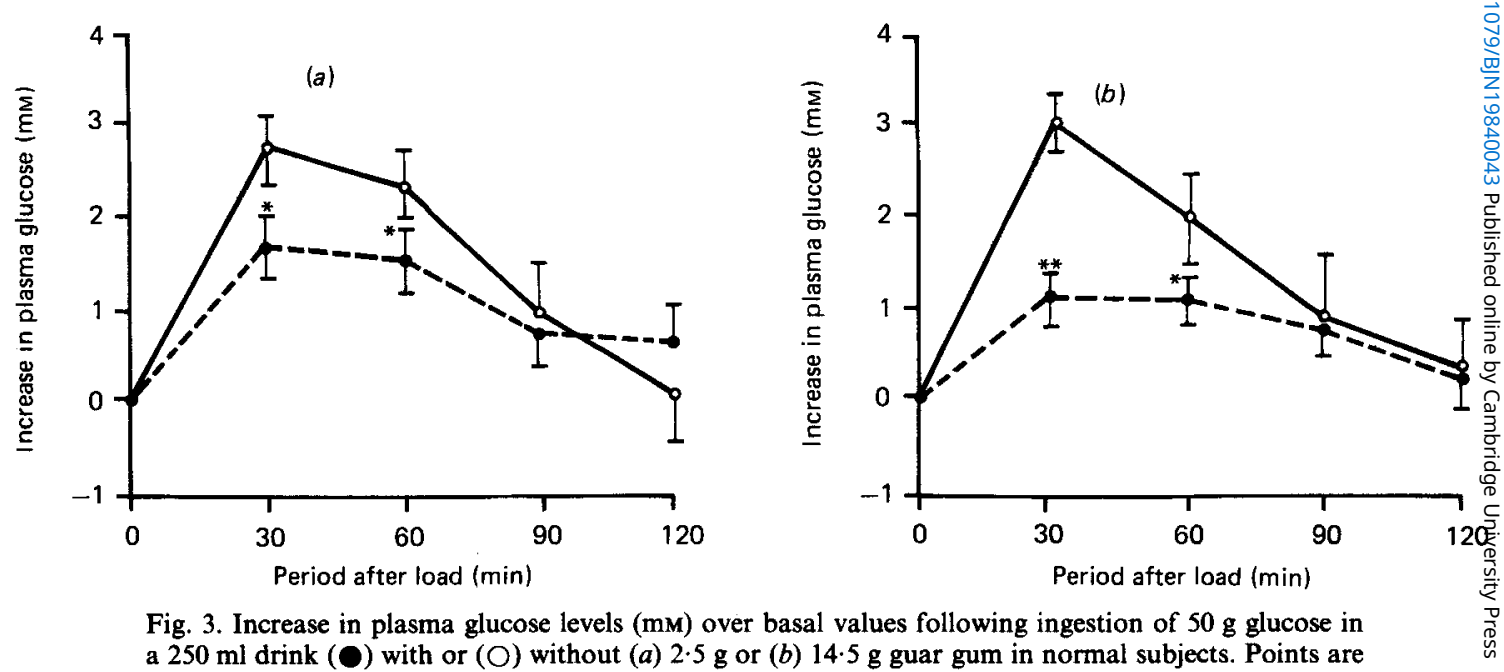

Fig. 3. Increase in plasma glucose levels (mM) over basal values following ingestion of $50 \mathrm{~g}$ glucose in a $250 \mathrm{ml}$ drink (O) with or $(O)$ without $(a) 2.5 \mathrm{~g}$ or $(b) 14.5 \mathrm{~g}$ guar gum in normal subjects. Points are mean values with their standard errors of the mean represented by vertical bars for eight observations.

* $P<0.05, * * P<0.01$.

out only if they gave written assurances that they were not pregnant and that they were using a reliable form of contraception. Moreover, studies using radioisotopes were only carried out during the first $10 \mathrm{~d}$ of the menstrual cycle.

\section{Statistical analysis}

Paired Student's $t$ test was used to assess the statistical significance of differences between control and test results and values for the power of the test were determined for each point (Altman, 1980).

\section{RESULTS}

Studies in normal subjects

\section{Plasma glucose}

Fybogel. Addition of $3.5 \mathrm{~g}$ or $7 \mathrm{~g}$ Fybogel to an oral glucose load of $50 \mathrm{~g}$ glucose in $250 \mathrm{ml}$ of solution produced no significant changes in postprandial plasma glucose levels (Fig. 1). However, the power of the test was low (less than $5 \%$ for $3.5 \mathrm{~g}$ Fybogel for each data point and less than $12 \%$ for $7 \mathrm{~g}$ Fybogel), suggesting large individual variations.

Metamucil. Addition of $7 \mathrm{~g}$ Metamucil to an oral glucose load of $50 \mathrm{~g}$ glucose in $250 \mathrm{ml}$ of solution produced no significant change in postprandial glucose levels (Fig. 2). However, the power of the test was less than $8 \%$.

Guar gum. Addition of 2.5 or $14.5 \mathrm{~g}$ guar gum to the oral glucose load significantly lowered plasma glucose values during the first hour after ingestion (Fig. 3).

\section{Plasma insulin}

Fybogel. Results for 3.5 and $7 \mathrm{~g}$ Fybogel studies are available for eight and five subjects respectively. Neither dose of Fybogel had any significant effect on plasma insulin levels following the oral glucose load (Fig. 4). However, the power of this test was less than $22 \%$.

Guar gum. Addition of 2.5 and $14.5 \mathrm{~g}$ guar gum to the glucose load significantly reduced the plasma insulin levels during the first hour after ingestion compared with the control studies (Fig. 5). 

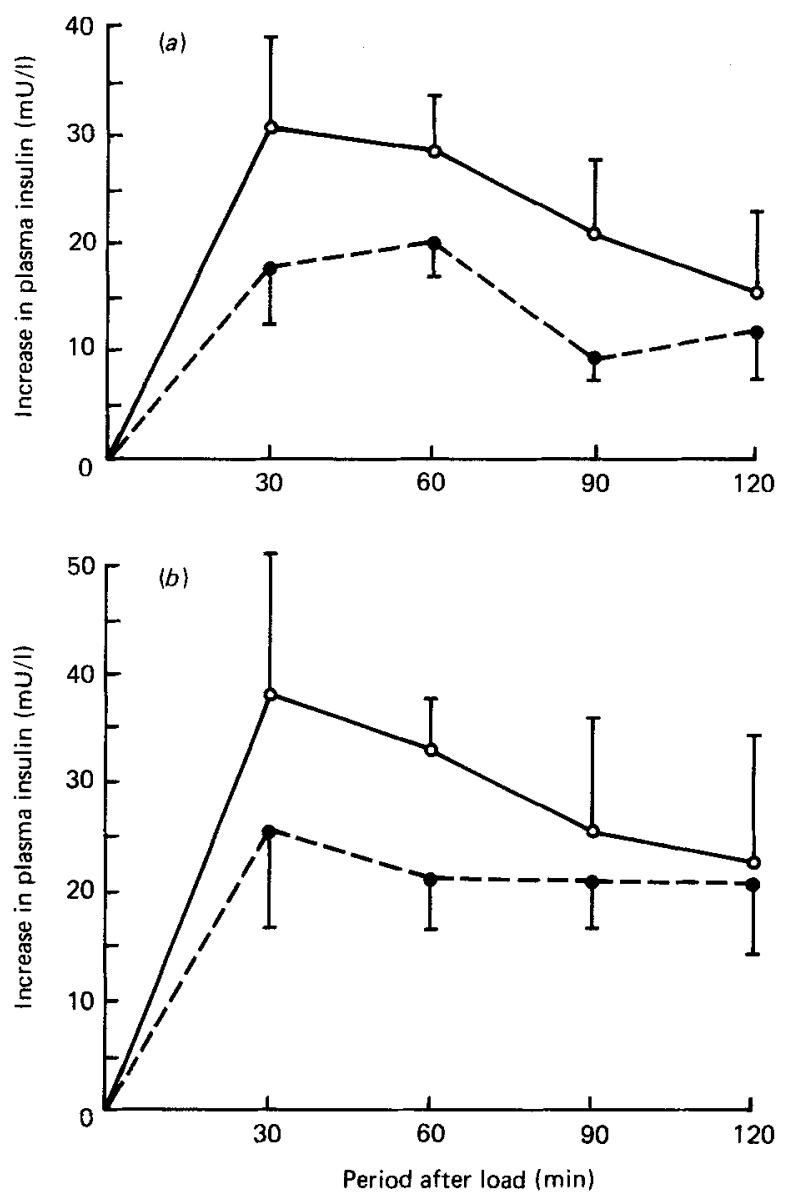

Fig. 4. Increase in plasma insulin levels $(\mathrm{mU} / \mathrm{l})$ over basal values following ingestion of $50 \mathrm{~g}$ glucose in a $250 \mathrm{ml}$ drink $(O)$ with or $(O)$ without $(a) 3.5 \mathrm{~g}$ or $(b) 7 \mathrm{~g}$ Fybogel in normal subjects. Points are mean values with their standard errors of the mean represented by vertical bars for seven $(a)$ or eight $(b)$ observations.

\section{Gastric emptying}

Fybogel. Neither 3.5 nor $7 \mathrm{~g}$ Fybogel added to the glucose load altered the half-time for the emptying of the solution from the stomach (Table 1), or the percentage of radiolabel emptied from the stomach at $30 \mathrm{~min}$ following ingestion.

Guar gum. Addition of $14.5 \mathrm{~g}$ to an oral glucose load did not alter the half-time for emptying of the glucose solution from the stomach (Table 1). Moreover, there was no significant linear correlation between change in gastric emptying half-times and change in peak increase in plasma glucose induced by addition of $14.5 \mathrm{~g}$ guar gum.

\section{Studies in diabetic patients}

Addition of $7 \mathrm{~g}$ Fybogel to the oral glucose load did not significantly alter either the plasma glucose levels or the plasma insulin levels (Fig. 6). However, the power of the statistical test was less than $12 \%$ in each case. Neither was there any significant change in the rate of gastric emptying after adding Fybogel to the drinks of the six patients in whom these measurments were undertaken (Table 1). 

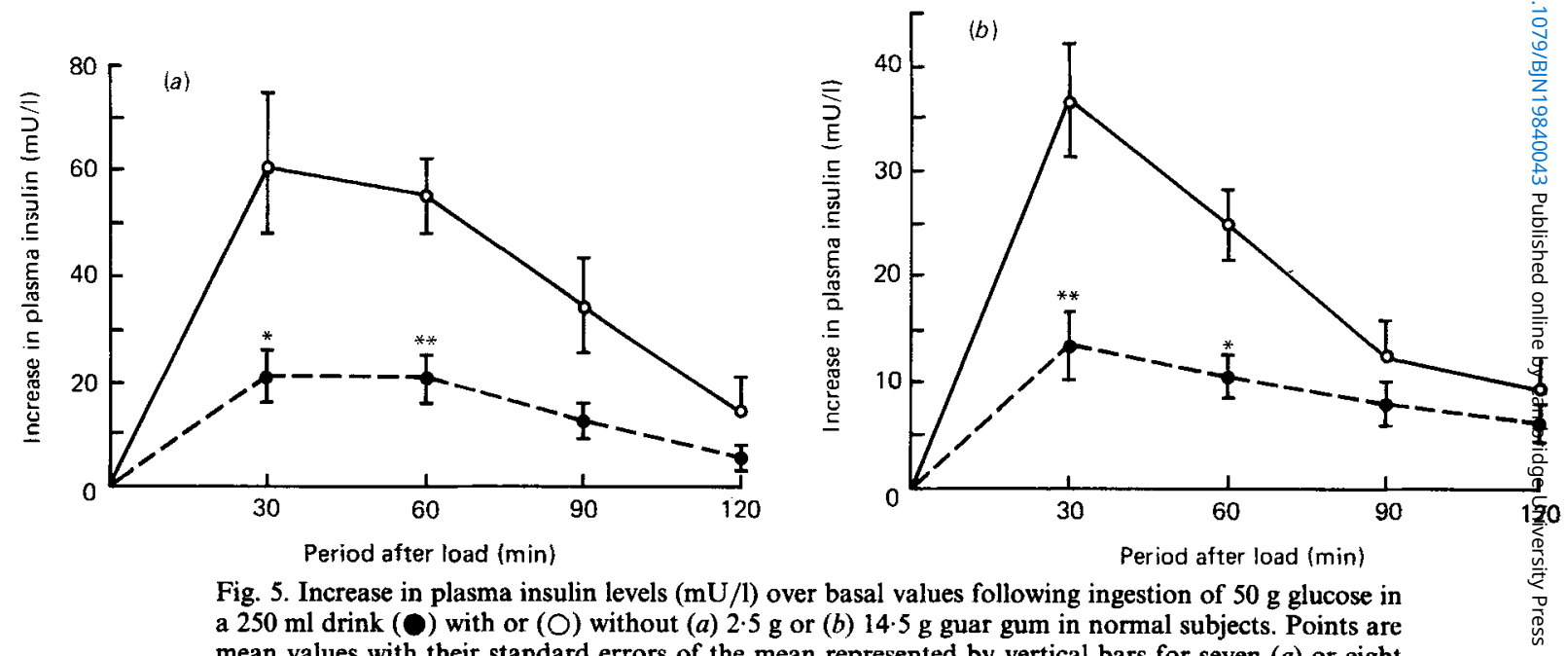

Fig. 5 . Increase in plasma insulin levels $(\mathrm{mU} / \mathrm{l})$ over basal values following ingestion of $50 \mathrm{~g}$ glucose in a $250 \mathrm{ml}$ drink (O) with or $(O)$ without $(a) 2.5 \mathrm{~g}$ or $(b) 14.5 \mathrm{~g}$ guar gum in normal subjects. Points are mean values with their standard errors of the mean represented by vertical bars for seven $(a)$ or eight (b) observations. * $P<0.05$, ** $P<0.01$.

Table 1. The effect of guar gum and Fybogel on half-times (min) for gastric emptying

(Mean values with their standard errors)

\begin{tabular}{|c|c|c|c|c|c|c|}
\hline \multirow[b]{2}{*}{ Material } & \multirow{2}{*}{$\begin{array}{l}\text { Weight } \\
\text { (g) }\end{array}$} & \multirow{2}{*}{$\begin{array}{l}\text { No. of } \\
\text { subjects }\end{array}$} & \multicolumn{2}{|c|}{ Control } & \multicolumn{2}{|c|}{ Test* } \\
\hline & & & Mean & SEM & Mean & SEM \\
\hline \multicolumn{7}{|c|}{ Normal subjects } \\
\hline Guar gum & $14 \cdot 5$ & 8 & $44 \cdot 7$ & $4 \cdot 6$ & $55 \cdot 8$ & $8 \cdot 7$ \\
\hline Fybogel & 3.5 & 9 & 59.9 & $11 \cdot 6$ & $56 \cdot 3$ & $12 \cdot 4$ \\
\hline & 7 & 13 & $63 \cdot 4$ & $15 \cdot 5$ & $55 \cdot 5$ & $6 \cdot 1$ \\
\hline \multicolumn{7}{|c|}{ Non-insulin-dependent diabetics } \\
\hline Fybogel & 7 & 6 & $76 \cdot 1$ & $6 \cdot 2$ & $73 \cdot 7$ & $15 \cdot 8$ \\
\hline
\end{tabular}

* There were no statistically significant differences $(P>0.01)$ between control and test results.

\section{Viscosity studies}

The viscosity measurements showed that at least four times more Fybogel was required to produce solutions of similar viscosity to those of guar gum at a shear rate of $50 / \mathrm{s}$ (Fig. 7).

\section{DISCUSSION}

These experiments failed to show any significant effect of ispaghula (Fybogel or Metamucil) on glucose tolerance or insulin levels in normal volunteers or any significant effect of Fybogel on the same measurements in patients with non-insulin-dependent diabetes mellitus. These results appear at variance with previous studies which showed that two different preparations of ispaghula (Metamucil and Lunelax), when taken before or together with a standard test meal, significantly reduced postprandial glucose levels in diabetic patients (Sartor et al. 1981; Florholmen et al. 1982). It seems unlikely that the formulation of ispaghula is responsible for this discrepancy since our results showed that Metamucil also had no significant effect on glucose tolerance. The reason why ispaghula should lower 

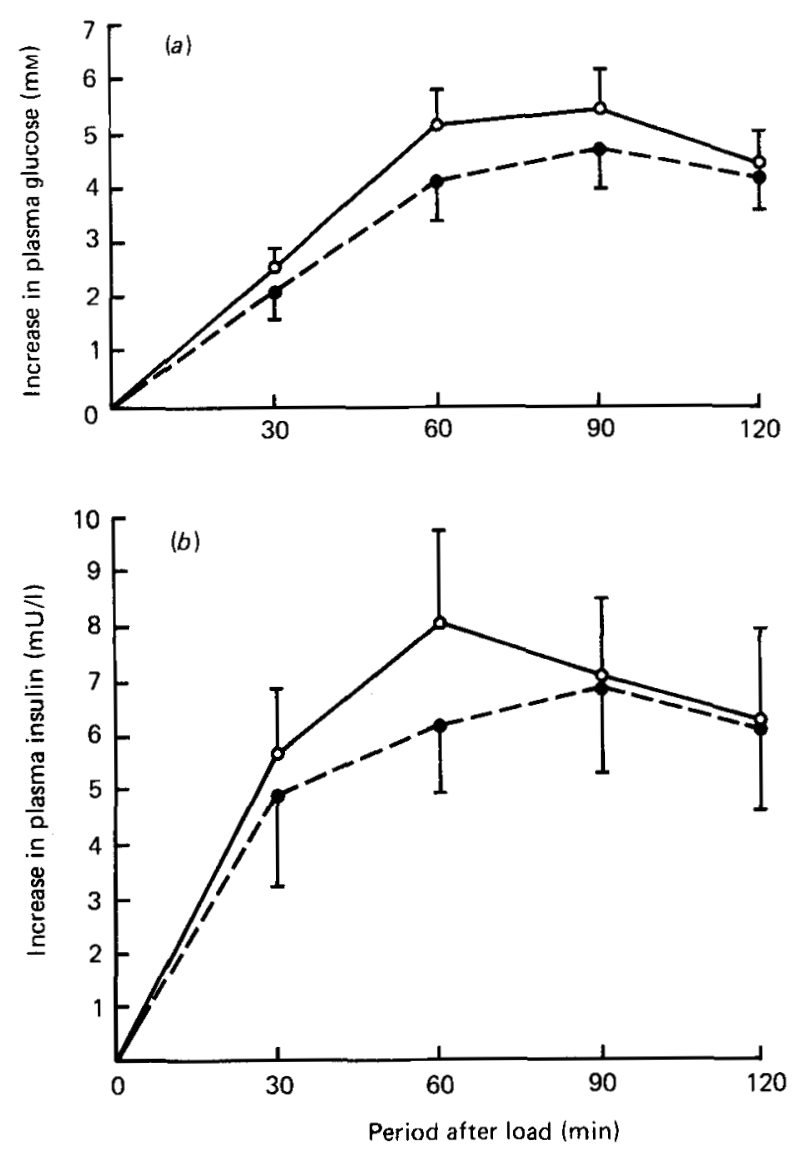

Fig. 6. Increase in (a) plasma glucose levels (mM) over basal values and $(b)$ increase in plasma insulin levels $(\mathrm{mU} / \mathrm{l})$ over basal values following ingestion of $50 \mathrm{~g}$ glucose in a $250 \mathrm{ml}$ drink $(O)$ with or $(O)$ without $7 \mathrm{~g}$ Fybogel in non-insulin-dependent diabetics. Points are mean values with their standard errors of the mean represented by vertical bars for fourteen observations.

glucose levels after a meal but not after a drink containing glucose is unclear. Possible explanations are that the combination of ispaghula with chyme may have a greater viscosity than ispaghula and a glucose drink or that the major effect of ispaghula may be to inhibit the action of amylase in digesting the starch in the meal.

A few studies have indicated that the effect of viscous polysaccharides on glucose levels following an oral glucose tolerance test is related to the viscosity of the gum used (Jenkins et al. 1978; Taylor et al. 1980). As Fybogel has a much lower viscosity than guar gum at a shear rate of $50 / \mathrm{s}$, it is perhaps not surprising that we could demonstrate no significant effect of this agent on glucose tolerance, although it is important to note that the power of the statistical test was low, indicating large individual variations. Higher levels of ispaghula may well improve glucose tolerance but doses above $7 \mathrm{~g}$ become extremely unpalatable. Guar gum, on the other hand, lowered glucose tolerance and reduced plasma insulin levels following an oral glucose load.

Previous studies with guar gum have used between 10 and $22.3 \mathrm{~g}$ of the material with standard glucose tolerance tests or carbohydrate meals (Jenkins et al. 1976, 1980; Holt et 


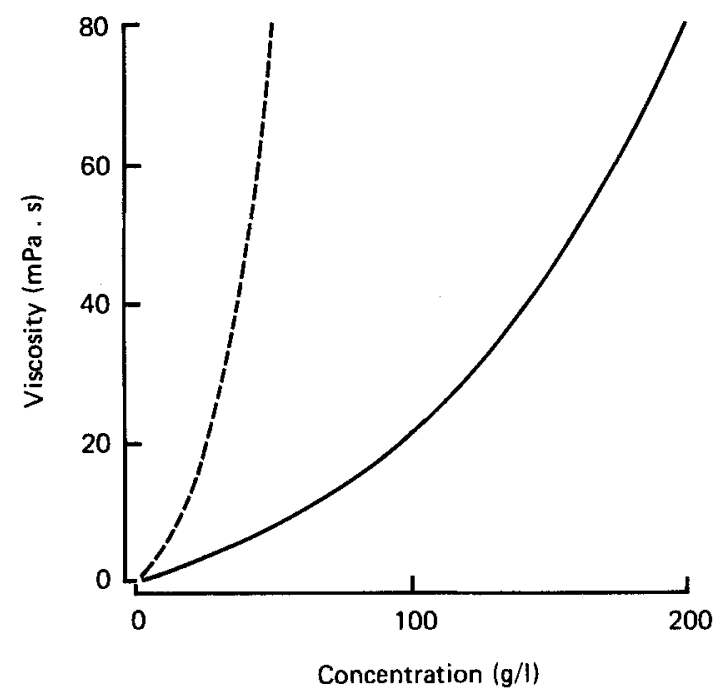

Fig. 7. The relationship between viscosity (mPa.s), measured at a shear rate of $50 / \mathrm{s}$, and concentration $(\mathrm{g} / \mathrm{l})$ of $(-\cdots)$ guar gum and $(\longrightarrow)$ Fybogel.

al. 1979; Morgan et al. 1979). Guar gum at this level is rather unpalatable and consequently the use of guar gum to improve glucose tolerance in diabetics has not become widespread. The present study shows that $2.5 \mathrm{~g}$ guar gum $(10 \mathrm{~g} / \mathrm{l})$ is almost as effective as $14.5 \mathrm{~g}(58 \mathrm{~g} / \mathrm{l})$ guar gum in lowering blood glucose levels, and we therefore suggest that the levels of guar gum previously used are excessive. It is probable that these large amounts of guar gum never became completely hydrated, so that much of the ingested guar gum may not have actually contributed towards its hypoglycaemic action.

\section{REFERENCES}

Altman, D. G. (1980). British Medical Journal 281, 1336-1338.

Blackburn, N., Redfern, J. S., Jarjis, H., Holgate, A. M., Hanning, I., Scarpello, J. H. B., Johnson, I. T. \& Read, N. W. (1984). Clinical Science and Molecular Medicine (In the Press.)

Florholmen, J., Arvidsson-Lenner, R., Jorde, R. \& Burhul, P. G. (1982). Acta Medica Scandinavica 212, $237-239$.

Gassull, M. A., Goff, D. V., Haisman, P., Hockaday, T. D. R., Jenkins, D. J. A., Jones, K., Leeds, A. R. \& Wolever, T. M. S. (1976). Journal of Physiology (London) 259, 52P-53P.

Holt, S., Heading, R. C., Carter, D. C., Prescott, L. F. \& Tothill, P. (1979). Lancet i, 636-639.

Jenkins, D. J. A., Leeds, A. R., Gassull, M. A., Cochet, B. \& Alberti, K. G. M. M. (1977). Annals of Internal Medicine 86, $20-23$.

Jenkins, D. J. A., Leeds, A. R., Wolever, T. M. S., Goff, D. V., Alberti, K. G. M. M., Gassull, M. A. \& Hockaday, T. D. R. (1976). Lancet ii, 172-174.

Jenkins, D. J. A., Wolever, T. M. S., Leeds, A. R., Gassull, M. A., Haisman, P., Dilawari, J., Goff, D. V., Metz, G. L. \& Alberti, K. G. M. M. (1978). British Medical Journal i, 1392-1394.

Jenkins, D. J. A., Wolever, T. M. S., Nineham, R., Sarson, D. L., Bloom, S. R., Ahern, J., Alberti, K. G. M. M. \& Hockaday, T. D. R. (1980). Diabetologia 19, 21-24.

Jones, T., Clark, J. C., Kocak, N., Cox, A. G. \& Glass, H. I. (1970). British Journal of Radiology 43, $537-541$. Morgan, L. M., Goulder, T. J., Tsiolakis, D., Marks, V. \& Alberti, K. G. M. M. (1979). Diabetologia 17, 85-89. Ostick, D. G., Green, G., Howe, K., Dymock, I. W. \& Cowley, D. J. (1976). Gut 17, 189-191.

Sartor, G., Carlstrom, S. \& Schersten, B. (1981). Acta Medica Scandinavica 656, Suppl. 51-53.

Taylor, R. H., Wolever, T. M. S., Jenkins, D. J. A., Ghafari, H. \& Jenkins, M. J. A. (1980). Gut 21 , A452.

Wahlqvist, M. L., Morris, M. J., Littlejohn, G. O., Bond, A. \& Jackson, R. V. (1979). Australia and New Zealand Journal of Medicine 9,154-158. 